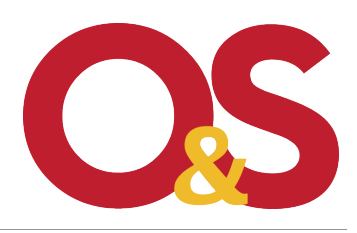

Revista Organizações \& Sociedade

2020, 27(92), $70-94$

\title{
Respostas a lógicas institucionais conflitantes: um estudo da participação nos lucros e resultados
}

(1) Autor(es) 2020

DOI 10.1590/1984-9270924

ISSN 1984-9230

Coping with conflicting institutional logics: a study of profit and gain sharing

www.revistaoes.ufba.br

NPGA, Escola de Administração

Universidade Federal da Bahia

Recebido: 23/07/2017

Rosana Carmen de Meiroz Grillo Gonçalves ${ }^{a}$

Aprovado: 24/10/2018

Mariana Simões Ferraz do Amaral Fregonesia

Vanessa Berlato Moreirab

aniversidade de São Paulo, São Paulo, SP, Brasil

'baculdade Anhanguera de Jundiaí, Jundiaí, SP, Brasil

\section{Resumo}

A participação nos lucros e resultados (PLR), desde a década de 1990, encontra-se inserida no cotidiano das empresas brasileiras. A intenção deste artigo foi investigar como uma organização responde a demandas institucionais conflitantes durante todo o período entre a adoção e o esmaecimento de uma prática. Foi realizado um estudo de caso longitudinal em indústria paulista que implantou e utilizou a PLR, abrangendo o período de 20 anos. Este artigo mostra como as respostas organizacionais podem se alterar ao longo do tempo. Aquiescência foi a resposta inicial, seguida por um processo de dissociação (decoupling) e diluição. Esta dinâmica de respostas deu-se em ambiente em que lógicas institucionais alteravam seu domínio relativo. No início, a participação nos lucros e resultados era pouco conhecida, sendo fortes os apelos favoráveis à sua implantação em consonância com a lógica de aumento de produtividade. Com o passar do tempo, contudo, houve o fortalecimento da lógica da PLR como instrumento de proteção social ao trabalhador. Mesmo fortalecida no campo institucional sua representação interna foi postergada devido a abalo externo (jo/t) e a estratégias de influência e cooptação utilizadas pelo grupo detentor de maior poder. Enquanto a literatura descreve que tal grupo impõe sua visão quando há diferentes representações internas das lógicas conflitantes, os resultados sugerem que tal fato ocorre mesmo quando somente uma lógica é representada internamente. 0 estudo contribui para o tratamento da representação interna das lógicas como um processo dinâmico, sujeito à interferência de atores e de jolts ambientais.

Palavras-chave: Participação nos lucros e resultados; Lógicas institucionais; Práticas organizacionais; Respostas estratégicas; Complexidade institucional.

\section{Abstract}

Since the 1990s, profit and gain sharing systems are part of the reality of Brazilian workers. The aim of the present study was to investigate how an organization responds to conflicting institutional demands throughout the period: from adoption to the decline of a practice. A twenty-years longitudinal case study was carried out in industrial company in São Paulo which implemented a profit and gain sharing system. This paper sheds light on how an organization response can change over time. Acquiescence was the initial response, followed by decoupling and dilution. This response dynamics sequence was observed during of transition, which represented a movement in the direction of the replacing of a dominant logic by another one. At the beginning of the period, the profit and gain sharing system was little known in Brazil, and there was a powerful appeal to implement it, consistent with the logic of increasing productivity improvement. Over time, however, the logic of social protection of workers became the prevailing logic in the field. Even so, its internal representation was 
postponed, due to external jolts, and due to the influence and co-optation strategies employed by the most powerful group. While literature has depicted that such a group imposes its views in the presence of multiple internal representations of conflicting logics, findings in this study suggest that the use of influence and co-optation can also happen in cases of a single internal representation. The study contributes to the treatment of the internal representation of the logics as a dynamic process, subject to the interference of actors and environmental jolts.

Keywords: Profit and gain sharing; Institutional logics; Organizational practices; Strategic responses; Institutional complexity.

\section{Introdução}

A perspectiva das lógicas institucionais representa um importante avanço na teorização em estudos organizacionais. Tem crescido o reconhecimento de que as organizações sofrem pressões de demandas ambientais conflitantes. Ainda assim, há lacunas no conhecimento de como lógicas, até certo ponto conflitantes, coexistem. Kraatz e Block (2008) explicam que as instituições definem as "regras do jogo" e uma organização que se depara com pluralismo institucional é aquela que joga diferentes jogos com diferentes regras. A organização e seus indivíduos, portanto, passam a lidar com tal pluralismo ao considerarem seus objetivos, ações e práticas.

O estudo das respostas a tais demandas conflitantes constituiu-se em uma linha de pesquisa com várias ramificações. Nos primeiros trabalhos a ênfase recaiu sobre respostas organizacionais ao pluralismo institucional baseadas na separação ou dissociação (decoupling) entre os procedimentos operacionais e as estruturas formais, nas quais eles estão inseridos (Meyer \& Rowan, 1977; Westphal \& Zajac, 2001; Boxenbaum \& Jonsson, 2008; Fiss \& Zajac, 2006). As organizações, simbolicamente, adotam as estruturas demandadas pelas instituições com vistas à obtenção de legitimidade, porém não há uma implantação efetiva das práticas correspondentes. Uma limitação desta linha de pesquisa refere-se à desconsideração da coexistência duradoura de demandas conflitantes. Organizações situadas em ambiente de lógicas conflitantes ao longo do tempo podem vir a ter sua dissociação exposta e não mais gozar da legitimidade pretendida.

Outra ramificação da pesquisa diferencia como as pressões de um ambiente institucional complexo afetam as organizações. Considera-se que, após passarem pelo campo, as pressões são filtradas por atributos da organização. Alguns artigos destacam como atributos: sua identidade (Kraatz \& Block, 2008; Battilana \& Dorado, 2010; Christiansen \& Lounsbury, 2013; Kodeih \& Greenwood, 2014) e outros, sua posição no campo (Greenwood \& Suddaby, 2006; Kostova, Roth \& Dacin, 2008).

Os trabalhos de Binder (2007), Lounsbury (2007), Besharov e Smith (2014) e de Pache e Santos (2010) constituem uma subdivisão da pesquisa voltada à proposição de modelos preditivos da resposta organizacional.

Pesquisas consideram que a presença de lógicas conflitantes amplia a agência, permitindo o exercício de escolhas que podem preterir prescrições institucionais tidas como certas (Friedland \& Alford, 1991; Dacin, Munir \& Tracey, 2010). Ocasio, Loewenstein e Nigam (2015) enfatizam que a experiência da complexidade institucional é socialmente construída, recebendo influências de indivíduos, organizações e campos institucionais. As organizações, além de receberem lógicas institucionais conflitantes filtradas por seus atributos, lidam, também, com tais pressões dependendo da articulação de várias dimensões organizacionais, tais como sua propriedade e estrutura (Almandoz, 2014; Bjerregaard \& Jonasson, 2014), suas representações políticas internas (Kim, Shin, Oh \& Jeong, 2007; Yu, 2013), as características de seus processos decisórios (McPherson 
\& Sauder, 2013), a construção de significado (Jay, 2013) e a facilidade de mudança em práticas de trabalho (Smets, Morris \& Greenwood, 2012).

Ressalta-se que nas ramificações dessa linha de pesquisa são pouco estudadas a dimensão temporal e a sequência de respostas organizacionais. A grande maioria dos autores tem assumido explícita, ou implicitamente, que a organização dará uma única resposta a demandas conflitantes (Greenwood, Raynard, Kodeih, Micelotta \& Lounsbury, 2011), o que parece insuficiente para explicar a realidade. O resgate da dimensão temporal feito em Raaijmakers, Vermeulen, Meeus e Zietsma (2015) e em Holm, Decreton, Nell e Klopf (2017) necessita ser ampliado para um melhor entendimento da sucessão de respostas organizacionais.

Este artigo vem ao encontro dessa necessidade. Sua relevância está na possibilidade de preencher lacunas do conhecimento sobre as respostas organizacionais mediante o resgate da dimensão temporal, do estudo de quando e por que as respostas podem ser proteladas, e, ainda, de como diferentes respostas se sucedem ao longo do tempo. $O$ objetivo deste estudo é investigar como uma organização responde a demandas institucionais conflitantes durante todo o período: da adoção ao esmaecimento de uma prática. A resposta estudada contempla a organização representada por grupos de indivíduos afastando-se do conceito da organização como um ator único representando um recipiente passivo (Dimaggio \& Powell, 1983), ou de resistência ativa (Oliver, 1991) e aproximando-se dos estudos que consideram que a resposta organizacional envolve a articulação de práticas e estruturas organizacionais. Durante o período estudado são descritos jolts, que representam perturbações transientes difíceis de serem previstas e que causam um grande impacto nas práticas organizacionais, podendo alterar ideias e crenças no clima institucional (Greenwood, Suddaby, \& Hinings, 2002; Greenwood \& Suddaby, 2006). Destaca-se que mudanças econômicas e na legislação recentes possibilitaram o estudo do impacto de jolts externos na representação interna de uma lógica. Uma sequência de respostas - aquiescência, decoupling e diluição - reverberou o fortalecimento da representação de uma das lógicas institucionais. A influência do grupo dominante foi fundamental na internalização de práticas e para que elas permanecessem inalteradas por um longo período. Tais resultados ora reafirmam, ora questionam as proposições de Oliver (1991), Lawrence, Winn e Jennings (2001), Kim et al. (2007), Pache e Santos (2010) e Crilly, Zollo e Hansen (2012), contribuindo para revisões e ampliações de modelos teóricos voltados ao entendimento das respostas organizacionais.

Para o atingimento do objetivo proposto, foram estudados a implantação e os impactos do acordo de participação nos lucros e resultados (PLR) de uma indústria paulista pelo período de 20 anos. 0 marco regulatório brasileiro da participação nos lucros e resultados (instituído no final de 1994) proporcionou às organizações um amplo espectro de possibilidades para a construção do significado de legitimidade. Destaca-se que, as regras sofreram sucessivas alterações legais até o ano 2000, e que, antes disso, não houve um entendimento claro do papel dos sindicatos. Ainda assim, desde o início, a maioria dos acordos tem sido firmada mediante negociação e concordância entre a empresa, uma comissão formada por seus trabalhadores e por representantes sindicais. Duas lógicas institucionais conflitantes associam diferentes significados à PLR: aumento à proteção social do trabalhador e da produtividade. Não foram encontradas publicações sobre acordos de PLR brasileiros que estudassem a dinâmica das respostas organizacionais, sequer estudos que adotassem a perspectiva longitudinal, sendo qualitativa a maior parte das pesquisas (Pina \& Stotz, 2011; Santos, 2011; Tadeucci, 2006; Martins, 2000). Este estudo, portanto, traz contribuição para o entendimento da institucionalização e posterior perda de valor dos acordos de participação nos lucros e resultados sob a ótica das possibilidades de resposta a demandas institucionais conflitantes em função de sua representação interna.

Este artigo está estruturado em duas seções que tratam do referencial teórico e dos aspectos metodológicos, seguidas de seções que apresentam os resultados obtidos. Nelas estão incluídos estudos das lógicas institucionais e da alternância de seu fortalecimento. Sendo, então, apresentado o caso em três fases: a adoção e internalização da PLR; seguida da fase de cristalização das regras e início do processo de decoupling; e da fase de declínio. Também é destacada a sequência de respostas, ao longo do período, em que ocorreram jolts 
externos. As seções finais apresentam a discussão dos resultados e das contribuições teóricas do estudo, e em sequência, temos a conclusão.

\section{Referencial teórico}

Lógicas institucionais podem ser definidas como crenças, regras e práticas, remetendo a uma ordem institucional e concedendo aos atores um repertório que define seus motivos (Friedland \& Alford, 1991). 0 trabalho de Thornton e Ocasio (2008) acrescenta ordens institucionais àquelas trazidas por Friedland e Alford (1991) e vai além, ao deixar de relacionar lógicas a ordens institucionais. Assim, possibilita que lógicas sejam analisadas coexistindo no campo institucional e nas organizações; e permite, por exemplo, que a lógica de mercado seja considerada ao serem analisadas escolas ou organizações que não visam lucro. Traduzidas em práticas e ideias, as lógicas institucionais moldam as regras do jogo e fornecem um discurso que populariza um conjunto de afirmativas. Lógicas podem definir como os atores interpretam a realidade, estabelecendo os critérios para a definição do que é um comportamento social legítimo (Thornton, Ocasio \& Lounsbury, 2015).

O pluralismo institucional é definido por Kraatz e Block (2008) como a presença de mais de uma lógica dominante no ambiente. Tal cenário pode submeter as organizações a prescrições incompatíveis relacionadas a "como agir" para obterem legitimidade (Greenwood et al., 2011). Também pode gerar competições entre grupos que têm afinidades e são leais a diferentes lógicas institucionais (Kraatz \& Block, 2008; Marquis \& Lounsbury, 2007).

Alguns autores associaram transitoriedade a lógicas institucionais distintas (Lounsbury, 2002; Thornton, 2002). Pesquisas mais recentes trazem evidências de que que o pluralismo institucional pode ser longevo (O'Mahony \& Bechky, 2008; Reay \& Hinings, 2009; Dunn \& Jones, 2010). Yu (2013, p. 107) afirma que os estudos no nível organizacional, em aposição aos estudos que se dão no nível do campo, trouxeram evidências empíricas de que diferentes lógicas se mantêm ao longo do tempo. De forma que, ao operarem em ambientes plurais, atores não agem segundo mandatos inquestionáveis, eles passam a ser compelidos a realizar escolhas (Seo \& Creed, 2002).

Respostas organizacionais ao pluralismo institucional

As organizações sob a tensão de múltiplas lógicas são capazes de considerar diferentes respostas organizacionais em sua busca por legitimidade (Reay \& Hinings, 2005; Smets et al., 2012).

O estudo seminal de Oliver (1991) tipifica respostas organizacionais sem ater-se ao pluralismo institucional. Sua contribuição se dá na aproximação do institucionalismo com a dependência de recursos. Nele são apresentadas possibilidades de respostas estratégicas variadas. Tal artigo estabeleceu um padrão de respostas adotadas por outros autores (Pache \& Santos, 2010; Raaijmakers et al., 2015). Oliver (1991) identificou antecedentes que impactam cinco tipos de respostas organizacionais estratégicas, quais sejam: aquiescer ou ceder, fazer concessões ou negociar, esquivar-se, manipular e desafiar. Segundo a autora, é mais provável que as organizações cedam às pressões externas quando elas forem compatíveis com os objetivos internos. A resistência às pressões deverá aumentar se a conformidade implicar em perda de autonomia. A segunda resposta é fazer concessões e corresponde a uma concordância parcial com os padrões institucionais, desde que os interesses da organização sejam preservados. Esquivar-se é o terceiro tipo de resposta que ocorre quando as organizações não atendem à demanda, ocultando a não-conformidade ou lançando mão de estratégias para postergarem o cumprimento da demanda. A não conformidade pode ser ocultada por meio de decoupling, ou seja, da adoção de estruturas formais de fachada que não têm qualquer influência sobre as práticas diárias da organização. A manipulação é a tentativa propositada e oportunista de influenciar, ou controlar pressões institucionais e o desafio é uma forma ativa de resposta que representa simplesmente a não conformidade. 
As respostas organizacionais passam a considerar o pluralismo institucional na perspectiva de diferentes artigos, entre os mais citados estão Seo e Creed (2002), Kraatz e Block (2008), Pache e Santos (2010), Greenwood et al. (2011), Smets et al. (2012) e Smets, Jarzabkowski, Burke e Spee (2015).

Respostas organizacionais considerando representação interna e estruturas de poder

Ao mesmo tempo em que as lógicas influenciam a cognição e a ação, os atores podem influenciar como as lógicas são instanciadas nas organizações (Besharov \& Smith, 2014; Thornton \& Ocasio, 2008). Powell e Colyvas (2008) defendem o estudo dos atores em suas rotinas diárias, uma vez que as instituições e suas lógicas subjacentes são sustentadas, alteradas e extintas pela ação de indivíduos em situações concretas.

Greenwood et al. (2011) ao diferenciarem a forma como as pressões de um ambiente institucional complexo afetam as organizações, estabelecem que após passarem pelo campo, elas são filtradas por vários atributos da organização.

Para Pache e Santos (2010) a resposta organizacional será definida em função de como as múltiplas lógicas estiverem representadas na organização. Segundo os autores, a representação interna das lógicas institucionais encerra o olhar e a percepção que os tomadores de decisão direcionam aos conflitos. Uma demanda institucional tem representação interna quando pelo menos um grupo está com ela comprometido ou alinhado.

Vários autores enfatizam a importância das estruturas de poder na forma como as lógicas são institucionalizadas nas organizações (Greenwood \& Hinnings, 1996; Lawrence, Mauws, Dyck \& Kleysen, 2005). Em se tratando de lógicas diferentes, tanto sua incorporação nas práticas essenciais da organização (Besharov \& Simth, 2014; Kim et al., 2007), como a posterior manutenção de seu status quo e a determinação de sua dominância (Thornton, 2004) dar-se-ão em função do poder dos grupos que as representam.

Pache e Santos (2010), ao discutirem respostas frente a demandas conflitantes internamente representadas, afirmam que na organização: "os grupos dominantes retêm poder suficiente para fazer com que sua visão prevaleça" (p. 465), não necessitando de desafiar as outras partes. Para com elas, adotarão estratégias de manipulação, com táticas de cooptação, influência e controle (Pache \& Santos, 2010, p. 467). Segundo Lawrence et al. (2001), tanto na adoção de novas práticas, como na perpetuação do status quo, é assumido implicitamente um conflito de interesses que revela o poder, relacionado à capacidade de influenciar o comportamento de outros, manipulando-se percepções, cognições e preferências. Este olhar intra-organizacional para a resolução das contradições envolvendo disputas políticas, que considera o uso da retórica e de outras capacidades para manipular percepções e cognições também é compartilhado por Smets et al. (2015), Greenwood e Suddaby (2006), Maguire e Hardy (2009) e Suddaby e Greenwood (2005).

Mais recentemente diferentes autores estudam a dinâmica temporal. Organizações podem demorar em responder às demandas institucionais. Além disso, não é considerada "a resposta organizacional" e sim "as respostas" que se sucedem ao longo do tempo. Smets et al. (2015) estudam como atores são capazes de equilibrar lógicas coexistentes ao longo do tempo. Raaijmakers et al. (2015) constataram que em situações de complexidade moderada ou alta, os tomadores de decisão protelam o atendimento às demandas (buffering), usando-se de prazos dilatados como escudos de proteção à cobrança por respostas. Holm et al. (2017) pesquisaram subsidiárias de multinacionais que, à medida em que pressões institucionais alternavam sua predominância, substituíam suas respostas estratégicas.

Ao longo do tempo, lógicas institucionais distintas podem contribuir para a desinstitucionalização ${ }^{1}$ de uma prática (Sandeep \& Ravishankar, 2014). Evidências comprovam que raramente uma prática é levada à

1. A desinstitucionalização é definida por Oliver (1992) como o processo pelo qual a legitimidade de uma prática organizacional institucionalizada é descontinuada ou desgastada, levando a prática a ter seu valor diminuído ou a extinguir-se. A autora sugere que tal processo seja desencadeado por mudanças políticas, sociais e funcionais. 
extinção total, pois sempre serão preservados elementos úteis para sua reconstrução ou re-invenção ou para o emergir de outras práticas semelhantes (Dacin, Dacin, Greenwood, Oliver, Sahlin \& Suddaby, 2008; Becker, 2014).

As referências citadas permitem afirmar que a investigação sobre respostas organizacionais a demandas institucionais foi inserida no estudo da coexistência de diferentes lógicas. Ao longo do tempo, o estudo de tais respostas tem incluído não apenas a perspectiva dos atributos da organização que influenciam sua representação interna, mas também sua sucessão de forma dinâmica. Lógicas institucionais distintas podem influenciar a estabilização, fortalecimento e até mesmo a desinstitucionalização de práticas.

\section{Aspectos metodológicos}

Autores têm tratado a adoção da PLR em estudos transversais considerando particularidades de diferentes países (Westphal \& Zajac, 1993; Poutsma, Ligthart \& Schouteten, 2005; Lavelle, Turner, Gunnigle \& McDonnell, 2012; Kabst, Matiaske \& Schmelter, 2006). Para o caso brasileiro, considerando o hábito da importação de modismos gerenciais do primeiro mundo (Caldas \& Wood, 1999; Motta, Alcadipani \& Bresler, 2001; Wood \& Caldas, 2002), e as adoções de práticas gerenciais de forma cerimonial, esta pesquisa optou por uma abordagem metodológica qualitativa em que pudesse ser considerada a trajetória da adoção ao longo do tempo.

O estudo da trajetória da adoção ao esmaecimento da PLR envolve conceitos, tais como poder e significado, que são difíceis de mensurar, requisitando uma abordagem qualitativa (Greenwood \& Hinings, 1996; Yu, 2013). Simultaneamente, a dinâmica de diferentes lógicas institucionais, constrangendo as escolhas da organização, reivindica uma abordagem mais orientada à historicidade dos fenômenos (Patton, 2002; Seo \& Creed, 2002). Assim, a estratégia de pesquisa adotada foi o estudo de caso longitudinal, juntamente com extensa pesquisa bibliográfica sobre mudanças no contexto da empresa, que explicassem possíveis fortalecimentos de lógicas conflitantes.

A pesquisa começou a ser delineada em 2006 quando foi definido que os estudos de caso iniciais seriam realizados em indústrias que não pertencessem ao setor automotivo, cujos acordos de PLR já haviam sido anteriormente estudados (Kafrouni, 2005; Bridi, 2006). Houve então a escolha de sindicatos com grande representatividade vinculados aos setores químicos, farmacêutico, de alimentos e bebidas e sucroalcooleiro atuantes no estado de São Paulo. Tais sindicatos foram visitados e indicaram indústrias com acordos de PLR considerados por eles como bem implantados. As indicações foram contatadas até a identificação de quatro delas que cumpriam os requisitos de um acordo de PLR bem elaborado e tinham disponibilidade para participar da pesquisa. Cada uma delas pertencia a um setor: sucroalcooleiro; bebidas e alimentos; farmacêutico e químico, na categoria plásticos. Em tais empresas foi realizado um estudo de caso inicial em 2007. A partir de então, seus acordos de PLR e outros documentos públicos continuaram a ser obtidos e analisados semestralmente. No ano de 2009 foi escolhida apenas uma dessas empresas para o estudo longitudinal, a indústria doravante denominada Quimplast, que produz e vende artefatos plásticos para o mercado interno e externo. 0 principal fator que levou à escolha foi seu pioneirismo na implantação da PLR, iniciada em 1996, aliado à consistência e regularidade das práticas associadas aos acordos de PLR. Tais características não foram encontradas nas outras três indústrias.

A Quimplast é uma indústria de mão de obra intensiva com pequena especialização dos empregados, o que torna permanente o esforço pela redução da taxa de rotatividade de mão de obra. 0 acordo de PLR da empresa apresentou resultados duradouros após sua implantação, descartando-se suspeitas relacionadas à possibilidade de uma implantação cerimonial ineficaz. 
Coleta de dados

Múltiplas fontes de dados foram utilizadas: observação, entrevistas, questionários, e dados extraídos de documentos. Esses últimos compreenderam documentos públicos - balanço patrimonial, demonstração de resultados, relatório de sustentabilidade (disponível somente a partir de 2008), acordos de PLR e notícias relacionadas à empresa, disponíveis no sítio do sindicato; e documentos internos - cartilhas para divulgação da PLR, relatórios e slides referentes ao acordo de PLR e sua evolução, bem como, atas de reuniões da Comissão de PLR e da eleição de novos membros.

A etapa inicial da coleta de dados foi realizada em 2007. Antes da coleta de dados in loco, foram recuperados, lidos e resumidos todos os documentos públicos da Quimplast relativos ao período de 1997 a 2007. As fontes de tais documentos foram o sindicato e sítios da internet, tais como: Imprensa Oficial do Estado de São Paulo onde são publicados balanços patrimoniais. A empresa só foi visitada após o estudo de tais documentos, de forma que foi possível maior inserção contextual e maior atenção aos significados socialmente construídos durante a visita. Na indústria, os pesquisadores valeram-se da observação participante para conhecerem os modos de relacionamento dos empregados entre si e entre os empregados e seus superiores, bem como outras características do ambiente de trabalho. Ressalta-se que as entrevistas foram realizadas por mais de um pesquisador, possibilitando a verificação cruzada, isto é, a triangulação de pesquisadores. Foram entrevistadas 15 pessoas, cinco representavam a administração da empresa, e 10 eram operadores ou supervisores de produção. Foram totalizadas 11 horas de entrevistas gravadas. Posteriormente, ao serem produzidos os relatórios com as entrevistas transcritas, também foram feitos contatos com os gerentes entrevistados, mediante telefonemas e emails, para esclarecimentos de dúvidas pontuais.

A segunda fase da coleta de dados compreendeu o período entre 2007 e 2011 . Nela foram sistematicamente coletados, semestralmente, documentos da empresa internos e públicos. Os documentos foram analisados segundo o mesmo padrão para a confecção de resumos usado na primeira etapa de coleta de dados.

A terceira fase ocorreu em 2012 com novas visitas motivadas pela análise dos documentos, que evidenciou redução de 50\% no montante distribuído a título de PLR, quando comparado ao ano anterior, sem expressiva queda concomitante de faturamento. Foram entrevistados três representantes da administração e nove operadores ou supervisores de produção, totalizando mais dez horas de entrevistas gravadas. Também foram coletados documentos internos relativos ao acordo de PLR, tais como slides de apresentações para empregados, cartilhas de esclarecimentos etc. Ainda, houve observação participante que permitiu a constatação de que a satisfação inicial com a PLR havia diminuído.

A quarta e última fase da coleta de dados compreende a aplicação de questionários com perguntas objetivas abertas e fechadas, em 2015, tendo sido obtidas 36 respostas de gerentes e operadores ou supervisores de produção. Esta última fase também abarca a continuidade da coleta e análise de documentos semestrais, do período de 2012 até o primeiro semestre de 2017, quando foram obtidos dados referentes a 2016.

Análise de dados

Foram selecionados fatos úteis para a análise dos destaques do contexto econômico e social. Paralelamente, os resumos dos documentos, dos apontamentos das observações dos pesquisadores e das transcrições das entrevistas gravadas e dos dados abertos colhidos nas entrevistas foram submetidos à análise de conteúdo. Destaca-se que, as entrevistas não foram estruturadas e que muitas das falas livres remetiam a acontecimentos ocorridos em anos anteriores. A análise de conteúdo selecionou tanto assuntos abordados de forma recorrente mediante análise de frequência, como assuntos abordados de forma pouco explicada, evasiva. Tais assuntos foram avaliados pela perspectiva das entrevistas, da observação e dos documentos, garantindo a triangulação dos dados. 
Em seguida, foi usado um método para o melhor agrupamento temporal, adaptado de Langley (1999), que prevê a repetição de três etapas até o atingimento do consenso entre os pesquisadores sobre o melhor agrupamento temporal. Na primeira etapa, após análise inicial do material compilado da empresa e dos destaques do contexto foram propostos quatro períodos de análise como agrupamento temporal provisório. $\mathrm{Na}$ segunda, o material compilado e os destaques do contexto foram associados aos períodos inicialmente definidos. Na etapa três foram realizadas as análises responsáveis pela rejeição da divisão em quatro períodos. Finalmente, todas as etapas foram repetidas com a aprovação consensual de três períodos de análise: (i) de 1996 a 2003; (ii) de 2004 a 2010 e (ii) de 2011 a 2016.

Segundo Friedland (2012), a perspectiva das lógicas institucionais, definidas como prescrições sociais que orientam o comportamento de atores, tornou-se um framework para a análise institucional em múltiplos níveis. Segundo Greenwood et al. (2011) e Zilber (2017), distintas lógicas institucionais sofrem refração nas estruturas e processos dos campos, havendo pertinência na análise da resposta organizacional produzida, e na análise de como as lógicas, após a refração, são vivenciadas nas organizações. Nesta pesquisa foram estudadas as respostas da organização às lógicas relacionadas à PLR e, também sua experiência associada a práticas locais. Dois grupos de atores tiveram suas percepções e práticas estudadas: o dos gerentes e o dos operadores e supervisores de produção.

Assim, particularmente, a partir dos relatos dos gerentes e operários e dos destaques do contexto enquadrados nos três períodos, foi refinada a extração do significado dos dados, sendo construída a cadeia lógica de evidências apresentada nos resultados.

\section{Resultados}

Aproximando-se e afastando-se da região de predominância, nesta seção são apresentadas as duas lógicas institucionais subjacentes aos acordos de PLR. Em seguida, o caso é apresentado em três períodos de análise. $O$ texto detalha quando e sob quais circunstâncias ocorreram a adoção, a cristalização e o esmaecimento da PLR, dando sustentação às respostas organizacionais identificadas. Os resultados, nos últimos parágrafos, apresentam as sucessivas respostas, destacando que ao longo do período ocorreram jolts externos, além da alternância no fortalecimento das lógicas.

\section{Lógicas institucionais subjacentes aos acordos de PLR}

As lógicas institucionais são estudadas no período que vai de 1996 a 2016. Na década de 1990, segundo Baltar (2003), o mercado de trabalho brasileiro possuía excesso de mão de obra pouco qualificada, baixa participação dos salários no custo de produção e enorme desigualdade na distribuição dos salários. Havia um contexto marcado pela desregulação comercial com maior abertura do mercado, por inovações tecnológicas e organizacionais, e pela redução de margens de lucro. Nesse cenário, foram feitas mudanças trabalhistas, com destaque para a implantação do banco de horas e da participação nos lucros e resultados. Após o plano real, em 1994, sem possibilidade de correção monetária, reajustes salariais perderam a centralidade que haviam alcançado no período anterior, voltando-se o movimento sindical, à negociação da PLR².

2. A PLR já estava prevista na legislação brasileira desde a Constituição de 1946, mas poucas empresas a implantavam. 0 grande incentivo ao seu uso ocorreu quando a Medida Provisória, MP 794 de 29 de dezembro de 1994, definiu que não haveria sobre a PLR incidência de encargos sociais nem de benefícios diretos (Martins, 2000). Depois de repetidas medidas provisórias semelhantes, no ano 2000 foi promulgada a Lei 10.101, que tornou obrigatória a negociação da PLR entre a empresa e seus empregados. Segundo Campinho (2009), ainda assim a implantação de um programa de PLR pode ser considerada facultativa, pois não há qualquer previsão de sanção no caso de recusa de uma das partes em negociá-lo. 
Em nosso caso duas lógicas institucionais subjacentes aos acordos de PLR puderam ser identificadas, sendo responsáveis por práticas, ou ausência de práticas, a elas associadas (Tabela 1). A primeira lógica institucional considera a PLR como um instrumento de ampliação da proteção social ao trabalhador, representando uma lógica normativa (Barley \& Kunda, 1992). Fonseca, Mendes e Machado (2014) recorrem à tradição constitucional brasileira de proteção ao trabalhador como parte mais frágil nas relações de produção para reiterar a PLR como direito inalienável e inafastável. As negociações de acordos de PLR, baseadas nesta lógica, advogam pelo estabelecimento de valores fixos a serem distribuídos, desvinculados de qualquer tipo de alcance de meta e, preferencialmente, de qualquer diferenciação entre os trabalhadores ${ }^{3}$.

Essa lógica também se sustenta na resistência cultural à avaliação quando se trata de estabelecer hierarquias dentro de grupos já formados (Barbosa,1996). Segundo Barbosa e Drummond (1994), no Brasil, os avaliados sempre terão restrições quanto às métricas de desempenho e terão dificuldades em aceitar a construção de hierarquias baseadas no mérito. A enorme desigualdade social favorece a atribuição de diferenças no desempenho a causas externas, sendo relegada a segundo ou terceiro plano a consideração dos talentos, dos esforços e da vontade de realizar de cada um, o que destitui de legitimidade a meritocracia.

A resistência à remuneração variável também considera os altos riscos que ela impõe ao trabalhador. Além dos riscos universais, da inclusão de metas cujo atingimento não depende das ações dos trabalhadores, tratados em diferentes pesquisas (Baker, Jensen \& Murphy, 1988; Baker, 2002; Gibbs, Merchant, Van Der Stede \& Vargus, 2009); também são acentuados os riscos decorrentes da assimetria de poder. A negociação local, feita entre os trabalhadores e a empresa, com a mediação do sindicato, segundo Comin e Castro (1998), pode abrir espaço para práticas despóticas de relações de trabalho por parte dos empregadores. Em processos judiciais há empresas acusadas de se esquivarem da negociação da PLR e de não darem a devida transparência às metas estabelecidas ${ }^{4}$. Segundo Pina e Sotz (2011) e Tadeucci (2006), há risco de que acordos de PLR, baseados no alcance de metas possam exaurir e desgastar os trabalhadores, trazendo prejuízo à sua saúde.

Atuando em consonância com a lógica de proteção social ao trabalhador, os indivíduos "se articulam buscando meios coletivos para a melhoria de toda a comunidade" (Alencar \& Oliveira, 2015). É defendido que os acordos estabeleçam a remuneração igualitária fixa, ou pelo menos que incluam expressivas parcelas fixas (Tabela 1). Nessa lógica, a PLR pode ser entendida como uma compensação pelo fim do reajuste dos salários, significando um $14^{\circ}$ salário ao trabalhador (Krein, 2007). Tais acordos estabelecem valores fixos, desvinculados de qualquer tipo de alcance de meta, inexistindo, portanto, o acompanhamento de metas, e outras práticas voltadas ao monitoramento dos valores a serem distribuídos.

Tabela 1 - Comparação entre as lógicas de proteção social e de aumento da produtividade

\begin{tabular}{l|l|l}
\hline & Proteção Social & Aumento da produtividade \\
\hline Missão & Preservar direitos do trabalhador. & $\begin{array}{l}\text { Crescer a produtividade/lucratividade, } \\
\text { aumentando a percepção do trabalhador } \\
\text { de que ele contribui para esse crescimen- } \\
\text { to. }\end{array}$ \\
\hline Fonte de legitimidade & $\begin{array}{l}\text { Reputação junto a sindicatos imbuídos de } \\
\text { um ideal igualitário e coletivista. }\end{array}$ & $\begin{array}{l}\text { Reputação junto a associações profissio- } \\
\text { nais, a sindicatos patronais e outros com } \\
\text { foco no papel da PLR no aumento da } \\
\text { produtividade. }\end{array}$ \\
\hline
\end{tabular}

3. Esta lógica criou uma peculiaridade brasileira, posto que no mundo todo, a expressão participação nos lucros e resultados implica em remuneração variável atrelada ao lucro ou a outros indicadores (Bryson, Freeman, Lucifora, Pellizzari \& Pérotin, 2013; Eurofound, 2007).

4. Um exemplo de contencioso é relatado no processo de número 35884.003885/2006-89 julgado pelo Conselho Administrativo de Recursos Fiscais (CARF). Disponível em: https://carf.fazenda.gov.br/sincon/public/pages/ConsultarlnformacoesProcessuais/consultarInformacoesProcessuais.jsf 


\begin{tabular}{l|l|l}
\hline & Proteção Social & Aumento da produtividade \\
\hline Princípio & Direito de todos. & Motivação pelo cumprimento de metas. \\
\hline \multirow{5}{*}{ Crenças e Valores } & $\begin{array}{l}\text { "Todos os filhos de Deus devem receber } \\
\text { o mesmo pagamento por seu trabalho" } \\
\text { (trecho de entrevista com operador de } \\
\text { máquina). }\end{array}$ & $\begin{array}{l}\text { O atingimento de metas é o elemento } \\
\text { fundamental da avaliação da força de } \\
\text { trabalho vinculada à meritocracia. }\end{array}$ \\
\cline { 2 - 3 } & $\begin{array}{l}\text { Fortalecimento do espírito de equipe e de } \\
\text { grupo, que pode sofrer danos quando há } \\
\text { comparação entre diferentes desempe- } \\
\text { nhos. }\end{array}$ & $\begin{array}{l}\text { A motivação trazida pelo atingimento } \\
\text { de metas e recebimento de incentivos é } \\
\text { essencial para o aumento da produtivi- } \\
\text { dade. }\end{array}$ \\
\cline { 2 - 3 } & $\begin{array}{l}\text { Excesso de competitividade pode levar à à } \\
\text { exaustão física e psicológica. }\end{array}$ & $\begin{array}{l}\text { Remuneração variável implica aumento } \\
\text { de comprometimento, de envolvimento e } \\
\text { do esforço do trabalhador na realização } \\
\text { de suas tarefas. }\end{array}$ \\
\cline { 2 - 3 } & \begin{tabular}{l} 
Eficácia de incentivos monetários. \\
\cline { 2 - 3 } Estratégias
\end{tabular} & $\begin{array}{l}\text { Ênfase em negociações e regras particu- } \\
\text { larizadas, definidas pela empresa e seus } \\
\text { trabalhadores, que pressupõem a PLR } \\
\text { como remuneração variável associada ao } \\
\text { alcance de metas. }\end{array}$ \\
\cline { 2 - 3 } & $\begin{array}{l}\text { "É da essência da PLR, a negociação } \\
\text { direta, nada mais justo e adequado do } \\
\text { que deixar a critério dos interessados, a } \\
\text { discussão de todas as regras. A comissão } \\
\text { de PLR decide como, quando e o que } \\
\text { querem fazer." (trecho de entrevista com } \\
\text { gerente de produção). }\end{array}$ \\
\hline
\end{tabular}

Fonte: Elaboração própria.

Na perspectiva da segunda lógica, a missão da PLR é o incremento da produtividade e consequentemente da lucratividade, mediante o aumento da percepção do trabalhador de que ele contribui para esse crescimento (Tabela 1). A lógica do aumento da produtividade defende que a PLR corresponda a uma remuneração variável e atrelada a metas, servindo como instrumento para que diferentes grupos de trabalhadores possam alinhar seus objetivos, harmonizados com os objetivos dos proprietários; o que deve implicar aumento de produtividade e de lucratividade. Ela é compatível com práticas de planejamento e controle, institucionalizadas como parte da gestão eficiente. Seus princípios propagam-se dentro de práticas de gestão em consonância com estudos voltados à economia dos incentivos, e com estudos vinculados às estratégias de remuneração.

A economia dos incentivos prescreve o incentivo monetário como complemento da automotivação, apoiando-se no uso da racionalidade econômica para a tomada de decisões. Uma de suas bases é a teoria descrita em Holmstrom e Tirole (1989), na qual a firma é composta por duas partes que possuem interesses conflitantes: o principal, que é o proprietário, e o agente. As ações do agente e a informação que ele possui não são observadas pelo principal. A fim de motivar o agente a selecionar ações que estão de acordo com os interesses do principal, este desenha um contrato de compensação, baseado em medidas de desempenho.

$\mathrm{Na}$ área de gestão, vários artigos clássicos americanos (Locke, Latham \& Erez, 1988; Locke \& Latham, 2002; Burke \& Terry, 2004) trouxeram argumentos favoráveis ao atingimento de metas como fator de estímulo a uma maior produtividade, trazendo argumentos de que a participação nos lucros e nos resultados associada a metas, poderia ser usada, até mesmo, para o fortalecimento da comunicação e estímulo a uma maior lealdade por parte dos trabalhadores. Também se apresentam na literatura nacional, argumentos favoráveis à PLR como remuneração variável, tais como melhor orientação ao trabalhador no desempenho de suas tarefas, 
aumento de seu foco, comprometimento e participação no grupo, e da intensidade de seus esforços (Wood Jr. \& Picarelli, 1996; Cardoso, 1999; Oliveira, 2001; Ducati \& Vilela, 2001; Reis \& Marques, 2004; Oyadomari, Lima, Aguiar \& Baldussi, 2012).

Alternância do fortalecimento das lógicas

O marco regulatório da PLR colaborou com o fortalecimento da lógica de aumento da produtividade, ao defini-la como instrumento de integração entre o capital e o trabalho, e de incentivo à produtividade. No ano de 1995 o número de acordos condicionados a metas já era significativo, correspondendo a cerca de 56\%, e o aumento desse tipo de acordo foi contínuo, situando-se na faixa de 80 a 86\% no período de 1998 até 2001 (Zylberstajn, 2002; 2003). O Departamento Intersindical de Estatística e Estudos Socioeconômicos (Dieese), em 2006, analisou uma amostra de acordos de PLR negociados em 2005 e os resultados mostraram que $81 \%$ dos acordos estavam condicionados a algum tipo de meta, e cerca de 19\% definiam valores fixos, isto é, não traziam vinculação a nenhuma meta.

No período de 2003 a 2011 foi observado um fortalecimento da lógica que considera a PLR como um instrumento de ampliação da proteção social ao trabalhador. Os sindicatos combativos passam a intensificar a estratégia de estabelecimento de um valor mínimo, de preferência fixo e desvinculado de metas, definido preferencialmente nas convenções coletivas de trabalho ${ }^{5}$. Passou a ser comum a proposição de que os valores fixos até mesmo se desvinculassem de faixas salariais; sendo a PLR considerada instrumento para melhor distribuição de renda e para promover igualdade entre os trabalhadores (Krein, 2007).

Em 2004, uma indústria não conseguiu negociar com o sindicato um acordo de PLR, porque o sindicato se recusou "a aceitar metas como condicionantes para o estabelecimento do valor da PLR e pressionou por um valor fixo anual" (Observatório Social, 2004, p. 23). Segundo pesquisa realizada em 2005, havia sindicatos que em suas negociações traziam como palavra de ordem: "por uma PLR fixa e sem metas" (Tadeucci, 2006). Krein (2007) relata que naquela época entre os principais embates quanto às negociações de PLR está a forma de distribuição: linear (fixa) ou diferenciada. Segundo o mesmo autor, a parcela fixa era defendida pelos sindicatos orientados a desenvolverem acordos baseados em princípios distributivos que assegurassem 0 pagamento de valores semelhantes para todos os trabalhadores (Dieese, 2006). Santos (2012), após análise de Acordos e Convenções sobre PLR entre 1994 e 2011, destaca que houve uma tímida mudança, no sentido de haver igualdade nos montantes distribuídos como PLR, devido ao aumento de parcelas fixas. Giffoni (2012) afirma que os sindicados se articulavam para defender a PLR como remuneração fixa. Santos (2011) mostra que, na evolução das convenções coletivas dos bancários, a maior conquista foi representada pela implantação da PLR fixa em 2007.

Apresentação do caso

\section{Fase 1: Adoção e internalização da PLR (de 1996 a 2003)}

No período, a Quimplast contava com cerca de mil empregados. Seu faturamento anual aumentou, oscilando entre 67 e 138 milhões de reais. Antes de 1996, era comum ser concedida pela Diretoria uma gratificação aos empregados, com mais de cinco anos de atuação na empresa, que não estava atrelada a nenhum indicador de produtividade. Tal gratificação espontânea foi extinta e segundo os gerentes "deu espaço

5. O ordenamento jurídico prevê que os acordos trabalhistas firmados nas Convenções Coletivas (que resultam de negociações entre diversos sindicatos de empregados e sindicatos de empregadores), quando mais benéficos ao trabalhador, prevaleçam sobre os acordos entre a empresa e seus empregados com a mediação dos sindicatos, ou seja, sobre os Acordos Coletivos de Trabalho (ACT). As Convenções costumam pactuar valores fixos, enquanto os ACTs optam por especificações detalhadas de indicadores e metas. 
à adoção em 1996 do plano de recompensa financeira baseado no desempenho implantado como PLR". Os entrevistados relataram que diante da obrigatoriedade da negociação de planos de PLR introduzida pela lei, havia a possibilidade de a empresa ter que se submeter a planos concebidos pelos sindicatos. A empresa então: "preferiu criar um plano próprio" que incluiu todos os empregados. Foram criadas estruturas em resposta à demanda institucional pela adoção da PLR. Isso pode ser tipificado pela criação da Comissão de Negociação formada por 10 trabalhadores e um dirigente sindical. Metade dos membros internos da Comissão foi indicada pela Diretoria da empresa. A outra metade foi definida por voto. 0 conjunto dos membros indicados é um subconjunto do grupo administrativo, composto por gerentes. 0 grupo dos eleitos é um subconjunto do grupo dos demais trabalhadores, que inclui trabalhadores de diferentes áreas, bem como encarregados do chão de fábrica.

As discussões iniciais da Comissão tiveram por tema a definição das etapas, desde a definição do montante a ser distribuído até sua alocação a cada trabalhador ${ }^{6}$. Destacam-se as metas coletivas referentes à produção:

- Eficiência no uso dos insumos,

- Horas de retrabalho, e

- Produtividade da mão de obra direta.

Todas têm o dobro do peso das metas de apoio à produção que são:

- Absenteísmo,

- Índice do custo da mão de obra na área de apoio, e

- Gastos administrativos específicos.

Nas falas de vários operadores e supervisores da produção foram destacadas inconsistências e omissões que indicavam a limitação de seu conhecimento sobre detalhes dessas regras. Após confrontar as falas com as regras contidas nos documentos, a limitação do conhecimento sobre o acordo de PLR foi selecionada como uma evidência válida. A gestão, entretanto, era familiar com as metas de produção que já costumavam ser monitoradas. Seu controle era feito dentro dos princípios de qualidade total, vinculado ao discurso de que todos deviam esforçar-se para fazer certo da primeira vez, evitando o retrabalho. A redução do desperdício era associada a práticas de arrumação e de limpeza.

Nas entrevistas com operadores e supervisores da produção ficou claro que se esforçar para a redução do retrabalho e do desperdício era tido como conduta adequada. Na visão dos gerentes: "alcançando as metas, vamos produzir a quantidade necessária com menor custo e com a qualidade desejada ... ficamos à frente da concorrência e todos vão ganhar com isso (sic)". A Comissão, frente à proposta da Diretoria pela continuação do uso dos indicadores de produção existentes, teve pouco espaço para a decisão do que seria monitorado. As regras de vinculação ao tempo de casa e à faixa salarial foram apresentadas pelos membros indicados pela Diretoria como inquestionáveis, uma vez que já eram consideradas em bônus anteriormente distribuído.

Aplicando as regras do acordo de PLR, a primeira distribuição de tais montantes ocorreu no ano de 1997 e deu início a uma fase de entusiasmo e satisfação dos empregados, permeada pela criação de novas práticas implantadas nos anos subsequentes. Periodicamente, os resultados parciais relacionados ao alcance

6. Na primeira etapa, são verificadas as condições para que haja a distribuição dos resultados, sendo a principal delas o alcance do piso mínimo de lucro bruto previamente fixado. Na segunda etapa, atingidas as condições para que haja a distribuição, é calculada a chamada quantia-a-distribuir que, por definição da Diretoria da empresa, oscila de 5,5\% a $8 \%$ do lucro bruto. Na terceira etapa, a quantia-a-distribuir será ponderada por um índice relativo ao alcance das metas coletivas para chegar-se ao valor a ser efetivamente distribuído. Posteriormente, na quarta etapa, tal valor será ponderado por indicadores individuais de desempenho e, seguindo as proporções das faixas salariais e o tempo de casa, será distribuído a cada um dos empregados. 
de metas passaram a ser divulgados em quadros de aviso. Foi implantada uma rotina de reuniões em que gerentes e supervisores acompanhavam o alcance das metas e discutiam os motivos de resultados deficitários. Os supervisores das áreas eram incumbidos de comunicar a seus subordinados o quanto faltava para o alcance das metas em cada indicador. Segundo um dos gerentes entrevistados:

... mediante tal comunicação, os empregados começavam a entender o que era relevante para a empresa. Sua rotina mudava, tendo sido introduzidas práticas relacionadas a discussões e conversas informais, que indicavam que havia sido assimilada a preocupação em alcançar as metas para conquistar uma recompensa, eles conseguiam perceber a valorização de seus esforços.

Tal mudança de rotina foi gradual, ocorrendo em período em que havia pouco conhecimento sobre as diferentes possibilidades de acordos de PLR. Muitos trabalhadores não sabiam que a PLR poderia representar um $14^{\circ}$ salário ou que poderia ser fixa. Havia dúvidas sobre a PLR nas empresas e no meio sindical, que de maneira geral, logo após a regulamentação, pouco contribuía para a definição dos acordos (Martins, 2000; Carvalho, 2001). Assim sendo, na primeira fase, a PLR é introduzida na empresa em consonância com a lógica do aumento da produtividade, assimilada pelos gerentes e também pelos operadores e supervisores da produção, que participavam assídua e ativamente de reuniões em que eram discutidas estratégias para o alcance das metas, ainda que desconhecessem as fórmulas matemáticas que traduziam em detalhes os critérios do acordo de PLR.

\section{Fase 2: Cristalização das regras e início do decoupling (de 2004 a 2010)}

Neste período, o faturamento anual da Quimplast foi crescente ${ }^{7}$, assim como seu número de empregados. Nos anos de 2005 a 2007, houve crescimento econômico no setor e no faturamento da empresa e nos montantes distribuídos como PLR. Em 2008 e 2009, o crescimento do faturamento da empresa foi quase 0 dobro do crescimento do seu setor. A variação do montante distribuído como PLR espelhou tal crescimento, fazendo com que nos anos de 2008 a 2010 fossem distribuídas as maiores quantias a título de PLR do período estudado.

Os gestores relataram a ampliação do contentamento com o plano. A satisfação com a qualidade do ambiente de trabalho e dos benefícios e incentivos recebidos foi atestada mediante questionários respondidos pelos empregados, que elegeram a empresa como uma das melhores para trabalhar nos anos de 2004 e 2005, em ordenamento promovido pela Revista Exame.

A partir do ano de 2005, o grupo administrativo propôs a inclusão de metas relativas ao absenteísmo e aos acidentes de trabalho no grupo das metas coletivas da produção. Houve tanta resistência, que, posteriormente, as metas relacionadas à redução de acidentes de trabalho foram retiradas.

A proporcionalidade à referência salarial também foi apontada como injusta pelos trabalhadores que possuíam as menores referências salariais. 0 grupo administrativo afirmou que uma sugestão de mudança, visando estabelecer menor ênfase nas faixas salariais, chegou a ser simulada, mas que não houve acordo para sua implantação. Segundo gerentes, a complexidade do plano faz com que suas simulações sejam feitas apenas pelo grupo administrativo.

Ainda em 2007, foi questionada a justiça da ponderação pelo tempo de casa do trabalhador na quarta etapa de distribuição. O principal argumento apresentado foi de que o resultado se refere ao ano recém-terminado e não ao passado remoto. Segundo esse raciocínio, todos os empregados que contribuíram para o resultado no ano em questão deveriam receber montantes iguais, sem a ponderação pelo tempo de casa. Os

7. O faturamento em reais aumentou: de cerca de 180 milhões em 2006 para cerca de 260 milhões em 2008 , e para 300 milhões em 2010. 
trabalhadores da Quimplast afirmaram que tanto o sindicato como outros membros da comunidade traziam relatos de que outras indústrias tinham conseguido pactuar acordos de PLR, em que a distribuição era de montantes total ou parcialmente fixos. Foi então sugerida a inclusão de uma parcela fixa no acordo de PLR.

Operadores e supervisores de produção, que mencionaram ter sugerido mudanças para o acordo cristalizado, reclamaram da demora para que elas fossem levadas às reuniões da Comissão de Negociação. A prática de simular o impacto das mudanças nos indicadores e metas foi sendo paulatinamente alterada. Respostas das simulações, inicialmente céleres, passaram a ser raras e demoradas. Também foi dilatado o intervalo entre as reuniões para a discussão do alcance de metas.

\section{Fase 3: Declínio (de 2011 a 2016)}

Em 2011, houve pequena queda no faturamento anual e os valores distribuídos como PLR foram reduzidos quase pela metade. Em toda esta fase, não houve distribuição de montantes tão expressivos como os dos anos de 2009 e 2010.

Neste período, a insatisfação com o plano foi muito grande. A partir de então, parece que não houve mais consenso quanto aos benefícios da PLR. Críticas foram encaminhadas à Comissão de Negociação da PLR de forma mais contundente. A pressão pela mudança não foi acolhida pelo grupo administrativo. Evitando maior enfrentamento, os dirigentes resolveram aumentar a "representação e participação dos empregados" na Comissão que passou de 12 para 22 membros.

A coleta de dados feita em 2015 mostrou que a satisfação com o plano era significativamente maior entre gerentes e demais empregados administrativos pertencentes às maiores faixas salariais, quando comparada à satisfação dos operadores e supervisores da produção. Também ficou clara a mudança nas práticas iniciais: resultados parciais relacionados ao alcance de metas não eram mais destacados nos quadros de aviso, que passaram a ser divulgados, mediante comunicação oficial, uma única vez no mês anterior ao pagamento da PLR. As discussões e conversas voltadas ao incentivo para cumprimento das metas já não ocorriam. Entre os descontentes foi externada a percepção de que o acordo de PLR "foi feito pela elite e para a elite... e a elite não cedeu".

Em lugar de ressaltar a importância da PLR, a Quimplast passou a ressaltar a importância dos benefícios indiretos (fringe benefits). Em seu relatório anual referente a 2016, a Quimplast, pela primeira vez, deixou de evidenciar o valor distribuído como PLR, passando a evidenciar em conjunto o valor por ela gasto com: assistência médica e odontológica, treinamentos, alimentação, cesta básica, participação nos resultados, transporte fretado, entre outros benefícios. A PLR passou formalmente a ser apenas um item de uma cesta de benefícios concedidos aos trabalhadores.

No ano de 2016, a Quimplast aventou eliminar a PLR, que após negociações foi mantida.

Sequência de respostas ao longo do período em meio a jolts externos e alternância no fortalecimento das lógicas

Na primeira fase, a lógica de proteção social ao trabalhador não estava clara a ponto de configurar uma resistência aos objetivos que levaram à adoção da PLR. Sem a representação interna significativa das duas lógicas, sem o conhecimento de diferentes possibilidades de acordos de PLR, e havendo sido propagado um discurso voltado à legitimação do alcance de metas, houve a aquiescência à lógica de aumento a produtividade como resposta organizacional. Não existindo coerção legal, o comportamento de aquiescência atendeu à disseminação da crença referente à adequabilidade da implantação de um acordo de PLR baseado em métricas de produtividade em consonância com o mito racional (Meyer \& Rowan, 1977). Mediante tal implantação, a Quimplast melhorou sua reputação junto a sindicatos patronais e a profissionais de outras indústrias perten- 
centes à sua cadeia produtiva, que ao aprovarem seu acordo de PLR Ihe conferiram legitimidade. Durante tal implantação não houve qualquer resistência interna, tendo sido manifestada satisfação geral com o acordo de PLR, tanto por parte do sindicato como por parte dos trabalhadores.

A segunda fase, que compreende o período de 2004 a 2010, foi marcada pela cristalização das regras do acordo de PLR. Embora no campo institucional tenha existido um fortalecimento da lógica de proteção social ao trabalhador, as regras que condicionavam a PLR ao alcance de metas não foram modificadas. A despeito da manutenção das regras, as práticas relacionadas ao acompanhamento de metas foram, paulatinamente, sendo modificadas, levando a um processo lento de configuração do decoupling como resposta organizacional.

Foi observado que o grupo dos operadores e supervisores da produção iniciou timidamente seu comprometimento com a lógica da PLR como instrumento de ampliação da proteção social ao trabalhador. Ressalta-se, entretanto, que o fortalecimento da representação interna dessa lógica encontrou obstáculos. Dois deles merecem destaque: um fato externo que funcionou como um jolt: o aumento abrupto da lucratividade da empresa; e a retórica do grupo administrativo dominante, enaltecendo a lógica da PLR voltada ao aumento da produtividade.

A lucratividade da empresa cresceu acompanhando o pico de crescimento econômico no Brasil. Os operadores e supervisores da produção, impactados pelo recebimento de quantias relativamente altas como PLR e impregnados pela retórica que legitima a lógica de aumento da produtividade, não se comprometeram significativamente com a lógica de proteção social ao trabalhador.

Ao longo do tempo, foram sendo infiltradas crenças relacionadas aos benefícios trazidos por uma PLR que distribuísse montantes fixos, desvinculados do alcance de metas. Foram vagarosamente desaparecendo as práticas voltadas à divulgação e discussão do quanto já havia sido alcançado das metas, e de estratégias para seu alcance. Relatos semelhantes a: "a gente nem pensa muito na PLR, só pensa em trabalhar"; "não se discute mais a PLR"; "só alguns recebem boa PLR", entre outros, além de mostrarem mudanças nas práticas, também mostraram a descrença na justeza dos acordos de PLR.

Mantendo-se as regras, atreladas ao alcance de metas, configurou-se o início da ruptura ou dissociação entre as práticas e os aspectos formais da adoção da PLR. Na prática, os trabalhadores não mais procuravam soluções para o alcance de metas, deixando paulatinamente de pensar nas metas e em suas possíveis melhorias. Portanto, a resposta organizacional passa a ser mais bem caracterizada pelo decoupling, considerando-se que a estrutura formal do acordo de PLR repleto de metas passa a não mais influenciar as práticas diárias.

Quando a legislação ${ }^{8}$ foi alterada em 2012, atenuando o montante recolhido de imposto de renda sobre a PLR, houve outra perturbação transiente, outro jolt. A regulação fez com que em toda sociedade brasileira, o contentamento com a PLR aumentasse, independentemente ser uma PLR fixa em sintonia com a lógica de proteção social ao trabalhador ou que se atrelasse ao alcance de metas, visando o aumento da produtividade. $\mathrm{Na}$ empresa foram envidados esforços para a revitalização de algumas práticas de controle de metas. Porém, tal esforço somente foi efetivo entre os empregados de maior renda, mais beneficiados pela isenção fiscal trazida pela lei. Para os outros trabalhadores, ainda persistiam descontentamentos relacionados à ausência de distribuição de parcelas fixas, não sendo restituída a importância de reuniões e ações voltadas ao atingimento de metas. O jolt trazido pela mudança da lei não conseguiu estancar o declínio observado no período de 2011 a 2016, apenas o desacelerou mediante seu impacto em alguns grupos da empresa.

Após 2012, grande parte das organizações pertencentes ao mesmo campo institucional que a Quimplast já tinha adotado acordos de PLR com distribuição linear ou mista. Tal fortalecimento da lógica de proteção social ao trabalhador foi assimilada pela empresa, aumentando-se as reivindicações para que fossem fixos os valores distribuídos ou que fixassem ao menos uma parcela. No entanto, o grupo de maior influência, não cedeu a tais pressões.

8. Medida Provisória n 597, de 26 de dezembro de 2012. Embora tal lei traga isenções fiscais a todos os trabalhadores, seu impacto é mais sentido pelo grupo dos melhores salários, sobre o qual incide uma alíquota maior de imposto de renda. 
A estagnação e recessão na economia ${ }^{9}$ e consequentes reduções no faturamento e no lucro da Quimplast, causaram diminuição dos montantes distribuídos como PLR, minando a percepção de sua importância. Fato é que a crise econômica atuou novamente como um jolt, que catalisou o processo de esmaecimento do valor e das práticas relacionadas à PLR. Foi exacerbado o problema do uso de métricas ruidosas, ou seja, que estão fora do controle do trabalhador (Gonçalves \& Tortoli, 2015), como mostra o depoimento: "os trabalhadores cumpriram as suas metas PLR em relação à qualidade e à produtividade, entre outros itens. Se o faturamento e o lucro foram baixos, não é responsabilidade dos trabalhadores (sic)".

As respostas da organização às pressões por mudanças foram em duas direções. Na primeira, houve a implantação de alterações superficiais no acordo de PLR e na maneira como ele era discutido. Por exemplo, houve o aumento do número de membros da Comissão de Negociação. Tal ação verificou-se como uma mudança de fachada, cerimonial, sugerindo o decoupling, posto que mesmo com mais membros, a Comissão não aumentou seu poder na negociação, mantendo-se inalteradas as regras do acordo de PLR.

Na segunda direção, foram usados de mecanismos de diluição (Dacin et al., 2008). Ao usar a tática de diluição, a Quimplast passa a mostrar para a sociedade que atende aos objetivos de proteção social ao trabalhador ao conceder-Ihes vários benefícios (fringe benefits), dentre os quais é apresentada a PLR. Ações dissimuladoras que propagam uma mudança inexistente e a ausência do significado, inicialmente atribuído à prática, faz com que a PLR perca seu valor. Ela se torna apenas mais um entre outros benefícios e é conduzida ao esmaecimento.

\section{Discussão dos resultados}

Foi estudada a sucessão de três respostas: da aquiescência, ao decoupling, e depois à diluição resultando no esmaecimento da prática. A resposta inicial de aquiescência à lógica de aumento da produtividade atendeu as três condições estabelecidas por Oliver (1991) para tal resposta:

- A implantação não prejudicou os interesses do grupo administrativo de maior poder;

- O conteúdo da demanda institucional associado à lógica da PLR como propulsora da produtividade foi compatível com o objetivo da organização; e

- Foi mantida a autonomia da indústria em relação à definição dos termos do acordo.

O acordo de PLR foi implantado com a utilização de indicadores de produção já previamente utilizados pela gestão. Tais indicadores espelhavam as estruturas formais da indústria, e eram coerentes com racionalidade social e localmente construída, sendo aceitos como prescrição de conduta apropriada. Foi reafirmado o mito racional, sendo demonstradas objetividade e imparcialidade visando o alcance da legitimidade (Meyer \& Rowan, 1977). O objetivo de aumento de produtividade tinha um significado positivo compartilhado, em diferentes graus, por todos os empregados.

Os resultados demonstram que a segunda resposta organizacional observada, a dissociação (decoupling), ocorreu em processo que levou anos e que recebeu influência do fortalecimento da lógica de proteção social ao trabalhador que paulatinamente aumentou sua representação interna. Tal resultado pode auxiliar na revisão e ampliação do modelo de Pache e Santos (2010), que estabelece apenas duas possibilidades: lógica internamente representada ou não. Foram apresentadas evidências que justificam o tratamento da representação da lógica de forma mais dinâmica, considerando variações na intensidade da representação.

9. No ano de 2014 , o PIB brasileiro teve um crescimento de $0,5 \%$ em relação ao ano anterior, iniciando um período de estagnação econômica e recessão revelada pela diminuição do PIB em dois anos consecutivos: $-3,8 \%$ no ano de 2015 e -3,6\% no ano de 2016 (Instituto Brasileiro de Geografia e Estatística, 2017). 
O estudo do decoupling como um processo também foi apresentado por outros autores (Tilcsik, 2010; Crilly et al., 2012), mas no caso estudado, além disso, foi possível analisar o efeito trazido por jolts externos. Os jolts externos ora atuaram como impedidores, ora como catalisadores para o fortalecimento da representação interna da lógica de proteção social que já havia se fortalecido no campo organizacional. Em período de crescimento econômico abrupto e aumento de lucratividade, as crenças e argumentos de proteção social foram deixados de lado por muitos trabalhadores. A recessão, em contraposição, foi um jolt catalisador para maior ressonância à lógica de proteção social, que favorecia o abandono de práticas relacionadas ao controle do alcance de metas. Tal abandono que configura o decoupling não foi estrategicamente planejado pela alta administração, nem foram criadas estruturas para esse fim. Antes, deveu-se à discricionariedade de supervisores em níveis hierárquicos inferiores, que trouxe inconsistências às políticas da empresa de ênfase e foco no controle do alcance de metas. Portanto, os resultados corroboram com a pesquisa mais recente de Crilly et al. (2012) que trata o decoupling como um processo que nem sempre é intencional, podendo resultar de comportamentos que surgem localmente, muitas vezes, contrários à orientação da alta administração. Tais resultados também fundamentam uma leitura mais crítica de pesquisas anteriores (Oliver, 1991; Pache \& Santos, 2010) em que o decoupling é tratado menos como um processo, e mais como um resultado, sendo fruto de escolhas estratégicas previamente decididas pela alta administração.

Não houve nenhuma tentativa de influenciar o campo institucional para isolar a organização de pressões externas. O que contraria o modelo teórico proposto por Kim et al. (2007) que afirmam que ao enfrentar pressões externas por mudança de uma prática organizacional já existente, os atores interessados em preservá-la tentarão isolar a organização das pressões externas.

O esmaecimento ou a diluição da prática não foram motivados pela introdução de novas práticas como estudado em Maguire, Hardy e Lawrence (2004), Greenwood et al. (2002) e Hinnings, Greenwood, Reay e Suddaby (2004). Também não foram motivados por problemas técnicos ou práticos relacionados ao seu funcionamento, ou por mudanças políticas (Oliver 1992). Foi fundamental, no entanto, a legitimidade social alcançada pela lógica de proteção ao trabalhador e sua assimilação por supervisores de fábrica com autonomia para extinguir as práticas de discussão do alcance das metas. Em consonância com os resultados apresentados em Becker (2014), todas as mudanças ocorreram vagarosamente e de forma não planejada, sendo fundamentais as decisões tomadas pelos supervisores.

Os resultados também apresentam aspectos da cooptação, em nível organizacional, que atrasaram a representação interna da lógica de proteção social ao trabalhador e que podem contribuir com o desenvolvimento teórico. Desde a fase inicial, o grupo de maior poder ao justificar os critérios e metas adotados no acordo de PLR, equiparou-a a um bônus anteriormente concedido, que se utilizava praticamente dos mesmos critérios e metas. Ao fazê-lo, conduziu a uma má interpretação do conceito, posto que a PLR não é um prêmio espontâneo e unilateral pago pela empresa. Foi usada linguagem persuasiva pelo grupo dominante para conceder maior legitimidade moral e cognitiva aos critérios, metas e práticas associadas à PLR (Lawrence et al., 2001; Suddaby \& Greenwood, 2005). Várias solicitações de mudanças nas regras do acordo de PLR também foram reprimidas de forma persuasiva. Outras tiveram sua consideração protelada mediante artifícios para ganhar-se tempo (buffering), postergando-se, por exemplo, a simulação do impacto de tal mudança na distribuição da PLR. Segundo o grupo dominante "antes de efetuar qualquer mudança era necessário entender os aspectos técnicos do acordo de PLR", enfatizando o poder relacionado ao conhecimento. Tais expedientes trouxeram à tona o papel do desequilíbrio de poder, permitindo que um grupo exerça influência e cooptação sobre os demais, atrasando o processo de representação interna de determinada lógica, no caso da lógica de proteção social ao trabalhador. Em Pache e Santos (2010) é afirmado que o grupo com maior poder usa de argumentação persuasiva, exerce influência e cooptação apenas na existência de representação interna das lógicas conflitantes. Foi verificado, contudo, que isso pode ocorrer mesmo antes que a lógica conflitante tenha representação interna. Fato que pode sugerir revisões e ampliações no modelo de Pache e Santos (2010). 


\section{Conclusão}

Este artigo traz uma contribuição para o melhor entendimento de como são dadas respostas organizacionais a lógicas conflitantes ao longo do tempo, mediante o estudo de uma implantação da PLR.

Foram identificadas duas lógicas conflitantes quanto ao entendimento de como deve ser distribuída a PLR: valores fixos iguais para todos ou como remuneração variável proporcional ao alcance de metas. Foi estudada a sucessão de três respostas: da aquiescência, ao decoupling, e depois à diluição resultando no esmaecimento da prática.

A mudança da aquiescência ao decoupling foi gradual e permitiu a observação de quando e por que as respostas podem ser proteladas. Além das movimentações das lógicas em relação à dominância, foram revelados jolts externos como catalizadores e impedidores para o fortalecimento da representação interna de uma lógica que já havia se fortalecido no campo organizacional. Quando impedidores, os jolts fizeram com que a organização lidasse de forma mais lenta com a nova pressão. Em síntese, lógicas institucionais conflitantes que alternam sua predominância ao longo do tempo podem ser mais ou menos representadas na organização e causar mudanças, dependendo da existência de outras perturbações ambientais. Também foi observada a imposição da visão do grupo detentor de maior poder, lançando mão de estratégias para influenciar e cooptar membros de outros grupos, atrasando a representação interna da lógica que não Ihe era favorável.

$\mathrm{O}$ artigo aumenta o entendimento da trajetória da PLR como prática no Brasil. Não foram encontrados outros estudos que adotassem a perspectiva longitudinal e uma microvisão no estudo da PLR. Embora as respostas organizacionais reflitam no campo institucional, não foi observada nenhuma tentativa por parte da Quimplast de tentar influenciar o campo institucional. Não houve, por exemplo, qualquer ação junto a sindicatos patronais e a entidades classistas para que fosse discutido o papel da PLR como incentivo à produtividade. Segundo Kim et al. (2007), quando uma organização enfrenta pressões externas por mudança de uma prática organizacional já existente, os atores interessados em preservá-la resistirão ou tentarão isolar a organização das pressões externas. No caso estudado, não foi captada nenhuma tentativa de isolamento da organização. 0 aprofundamento das razões para tal comportamento sugere futuras investigações que concorram para um melhor entendimento da relação entre indústrias nacionais e seu campo institucional.

Algumas limitações desta pesquisa remetem à coleta de dados, uma vez que mais horas de observação não estruturada teriam sido úteis para melhor entendimento da criação de significado, e do exercício de poder. Embora a pesquisa estude o fenômeno de forma longitudinal, as entrevistas e a aplicação de questionários e observações foram feitas de forma pontual, ainda que os entrevistados sempre fossem encorajados a transmitirem sua visão ao longo do tempo.

Em estudos futuros, que considerem a complexidade institucional e onde haja esforço para serem reconhecidos os mecanismos causais da sucessão de diferentes respostas organizacionais, sugere-se que juntamente com a dinâmica de fortalecimento de lógicas institucionais distintas continuem a ser estudados os reflexos das perturbações ambientais sob a forma de jolts. Também é sugerida uma investigação mais aprofundada dos mecanismos intra-organizacionais de cooptação, em especial analisando-se discursos verbais em que se sobressai o uso de recursos persuasivos.

\section{Referências}

Alencar, J. L. \& Oliveira, M. A. (2015). As CEBs à luz da teologia da libertação e sua relação com os movimentos sociais. Anais do Simpósio da Associação Brasileira de História das Religiões, Juiz de Fora, RJ. Brasil.

Almandoz, J. (2014). Founding teams as carriers of competing logics: When institutional forces predict banks' risk exposure. Administrative Science Quarterly, 59(3), 442-473. doi:10.1177/0001839214537810. 
Baker, G. (2002). Distortion and risk in optimal incentive contracts. Journal of Human Resources, 37(4), 728-751. doi:10.2307/3069615.

Baker, G. P., Jensen, M.C. \& Murphy, K.J. (1988), Compensation and incentives: Practice vs. theory. The Journal of Finance, 43, 593-616. doi:10.1111/j.1540-6261.1988.tb04593.x.

Baltar, P. E. A. (2003). Estrutura econômica e emprego urbano na década de 1990. In: M. W. Proni, \& Henrique, W. (Coord.), Trabalho, mercado e sociedade: O Brasil nos anos 90 (pp.107-152). São Paulo: Editora UNESP.

Barbosa, L. (1996). Meritocracia à brasileira: 0 que é desempenho no Brasil? Revista do Serviço Público, 47(3), 58-102.

Barbosa, L. N. H., \& Drummond, J. A. (1994). Os direitos da natureza numa sociedade relacional: reflexões sobre uma nova ética ambiental. Revista Estudos Históricos, 7(14), 265-290.

Barley, S., \& Kunda, G. (1992). Design and devotion: Surges of rational and normative ideologies of control in managerial discourse. Administrative Science Quarterly, 37(3), 363-399. doi:10.2307/2393449.

Battilana, J., \& Dorado, S. (2010). Building sustainable hybrid organizations: The case of commercial microfinance organizations. The Academy of Management Journal, 53(6), 1419-1440. doi.org/10.5465/ amj.2010.57318391.

Becker, S. D. (2014). When organisations deinstitutionalise control practices: A multiple-case study of budget abandonment, European Accounting Review, 23(4), 593-623, doi: 10.1080/09638180.2014.899918.

Besharov, M. L., \& Smith, W. K. (2014). Multiple institutional logics in organizations: Explaining their varied nature and implications. Academy of Management Review, 39(3), 364-381. doi:10.5465/amr.2011.0431

Binder, A. (2007). For love and money: Organizations' creative responses to multiple environmental logics. Theory and Society, 36(6), 547-571. doi:10.1007/s11186-007-9045-x.

Bjerregaard, T., \& Jonasson, C. (2014). Organizational responses to contending institutional logics: The moderating effect of group dynamics. British Journal of Management, 25(4), 651-666. doi:10.1111/14678551.12014.

Boxenbaum, E., \& Jonsson, S. (2008) Isomorphism, diffusion and decoupling. In: R. Greenwood, et al. (Coord.), The Sage handbook of organizational institutionalism (pp. 78-98). London: Sage.

Bridi, M. A. (2006). Ação sindical, acordos coletivos e condições de trabalho na moderna indústria automobilística do Paraná. In: S. M. Araújo (Org.), Trabalho e capital em trânsito: A indústria automobilística no Brasil (pp. 165-191). Curitiba: Editora UFPR.

Bryson, A.; Freeman, R.; Lucifora, C.; Pellizzari, M., \& Pérotin, V. (2013). Paying for performance: incentive pay schemes and employees' financial participation. In: T. Boeri, C. Lucifora, \& K. J. Murphy, Executive remuneration and employee performance-related pay: A transatlantic perspective (p. 121). Oxford: Oxford University Press. doi:10.1093/acprof:oso/9780199669806.011.0002

Burke, L. A., \& Terry, B. (2004). At the intersection of economics and HRM: An argument for variable pay schemes. American Business Review, 22(1), 88-92.

Caldas, M. P., \& Wood, T. Jr. (1999). Para inglês ver: Importação de tecnologia gerencial no Brasil. In: M. Caldas, \& T. Wood Jr., Transformação e realidade organizacional: Uma perspectiva brasileira (pp. 27-44). São Paulo: Atlas.

Campinho, F. A. R. (2009). Participação nos lucros e resultados: Subordinação e gestão da subjetividade. São Paulo: LTR. 
Cardoso, L. R. (1999). A participação nos lucros como componente de um sistema de remuneração estratégica um estudo de caso. Trabalho apresentado em Seminários de Administração - SemeAd, 2. São Paulo: PPGA/FEA/USP.

Carvalho, A. Neto. (2001). A negociação da participação nos lucros e resultados: Estudo em quatro setores dinâmicos da economia brasileira. Revista de Administração Contemporânea, 5(1), 195-214.

Christiansen, L. H., \& Lounsbury, M. (2013). Strange brew: Bridging logics via institutional bricolage and the reconstitution of organizational identity. In: M. Lounsbury, \& E. Boxenbaum, (Ed.), Institutional Logics in Action, (pp. 199-232, Research in the sociology of organizations, Vol. 39, Part B). Bingley: Emerald Group Publishing. doi.org/10.1108/S0733-558X(2013)0039AB020

Comin, Á. A., \& Castro, N. A. (1998). As novas esferas da regulação do trabalho e o dilema sindical. São Paulo em Perspectiva, 12(1), 45-52.

Crilly, D., Zollo, M., \& Hansen, M. T. (2012). Faking it or muddling through? Understanding decoupling in response to stakeholder pressures. Academy of Management Journal, 55(6), 1429-1448. doi:10.5465/ amj.2010.0697

Dacin, M. T., Dacin, P. A., Greenwood, R., Oliver, C., Sahlin, K., \& Suddaby, R. (2008). Traditions as institutionalized practice: Implications for deinstitutionalization. In: R. Greenwood, C. Oliver, R. Suddaby, \& K. Sahlin, The Sage handbook of organizational institutionalism (pp. 327-352). London: SAGE. doi: $10.4135 / 9781849200387$.

Dacin, M. T., Munir, K., \& Tracey, P. (2010). Formal dining at Cambridge Colleges: Linking ritual performance and institutional maintenance. Academy of Management Journal, 53(6), 1393-1418. doi:10.5465/ amj.2010.57318388

Departamento Intersindical de Estatística e Estudos Socioeconômicos. (2006). Participação dos trabalhadores nos /ucros ou resultados das empresas 2005. Disponível em: http://www.dieese.org.br/esp/pesquisasindi$\mathrm{cal} /$ pesquisasindical.xml.

DiMaggio, P. J., \& Powell, W. W. (1983). The iron cage revisited: Institutional isomorphism and collective rationality in organizational fields. American Sociological Review, 48(2), 147-160.

Ducati, E., \& Vilela, E. S. (2001). A Participação nos lucros ou resultados e a avaliação de desempenho. Trabalho apresentado em Encontro Anual da Associação Nacional dos Programas de Pós-Graduação em Administração, 25. Campinas: ANPAD.

Dunn, M. B., \& Jones, C. (2010). Institutional logics and institutional pluralism: The contestation of care and science logics in medical education, 1967-2005. Administrative Science Quarterly, 55(1), 114-149. doi:10.2189/asqu.2010.55.1.114

Eurofound. (2007). Employee financial participation in the New Member States. Recuperado de https://www. eurofound.europa.eu/sites/default/files/ef_files/docs/eiro/tn0701018s/tn0701018s.pdf.

Fiss, P. C., \& Zajac, E. J. (2006). The symbolic management of strategic change: Sensegiving via framing and decoupling. Academy of Management Journal, 49(6), 1173-1193. doi:10.5465/AMJ.2006.23478255

Fonseca, M. H., Mendes, G. A. dos S., \& Machado, G. C. (2014). Participação dos empregados nos lucros ou resultados da empresa sob a ótica constitucional: Direito do trabalhador ou faculdade do empregador? Revista de Informação Legislativa, 51( 204), 163-178.

Friedland, R. (2012). The Institutional logics perspective: A new approach to culture, structure, and process. M@n@gement, 15(5), 583-595. doi:10.3917/mana.155.0583. 
Friedland, R., \& Alford, R. R. (1991). Bringing society back in: Symbols, practices, and institutional contradictions. In: W. Powell, \& P. Dimaggio (Orgs.), The new institutionalism in organizational analysis (p.232-265). Chicago: University of Chicago Press.

Gibbs, M. J., Merchant, K. A., Van Der Stede, W. A., \& Vargus, M. E. (2009). Performance measure properties and incentive system design. Industrial Relations, 48(2), 237-264. doi:10.1111/j.1468-232X.2009.00556.X

Giffoni, C. (2012). Sindicatos querem livrar participação do lucro de IR. Valor econômico. São Paulo, p. E2, 22/02/2012.

Gonçalves, R. C. M. G., \& Tortoli, J. P. (2015). Características de indicadores de desempenho em sistemas de incentivo do setor automotivo. Revista Produção Online, 15(3), 999-1020.

Greenwood, R., \& Hinings, C. R. (1996). Understanding radical organizational change: Bringing together the old and the new institutionalism. Academy of Management Review, 21(4), 1022-1054. doi:10.5465/ AMR.1996.9704071862

Greenwood, R., \& Suddaby, R. (2006). Institutional entrepreneurship in mature fields: The big five accounting firms. Academy of Management Journal, 49(1), 27-48. doi:10.5465/AMJ.2006.20785498

Greenwood, R., Raynard, M., Kodeih, F., Micelotta, E. R., \& Lounsbury, M. (2011). Institutional complexity and organizational responses. Academy of Management Annals, 5(1), 317-371. doi:10.1080/1941652 0.2011 .590299

Greenwood, R., Suddaby, R., \& Hinings, C. R. (2002). Theorizing change: The role of professional associations in the transformation of institutionalized fields. Academy of Management Journal, 45(1), 58-80. doi: $10.2307 / 3069285$

Hinnings, C. R., Greenwood, R., Reay, T., \& Suddaby, R. (2004). Dynamics of change in organizational fields. In: M. S. Poole, \& A. H. Van de Ven. (Eds.), Handbook of organizational change and innovation (pp. 304-323). Oxford: Oxford University Press.

Holm, A. E., Decreton, B., Nell, P. C., \& Klopf, P. (2017). The dynamic response process to conflicting institutional demands in MNC subsidiaries: An inductive study in the sub-saharan african E-commerce sector. Global Strategy Journal, 7(1), 104-124. doi:10.1002/gsj.1145

Holmstrom, B. R., \& Tirole, J. (1989). The theory of the firm. Handbook of industrial organization, 1, 61-133.

Instituto Brasileiro de Geografia e Estatística. (2017). Sistema de Contas Nacionais. Disponível em: http://biblioteca.ibge.gov.br/visualizacao/livros/liv98781.pdf.

Jay, J. (2013). Navigating paradox as a mechanism of change and innovation in hybrid organizations. Academy of Management Journal, 56(1), 137-159. doi:10.5465/amj.2010.0772

Kabst, R., Matiaske, W., \& Schmelter, A. (2006). Financial participation in british, french and german organizations: A neoinstitutionalist perspective. Economic and Industrial Democracy, 27(4), 565-585. doi:10.1177/0143831X06068994

Kafrouni, M. A. S. (2005). A participação nos lucros e resultados na indústria automobilística do Paraná: um sistema de trocas para além das mercadorias (Dissertação de Mestrado). Departamento de Ciências Sociais, Universidade Federal do Paraná. Disponível em: https://acervodigital.ufpr.br/handle/1884/13439.

Kim, T. Y., Shin, D., Oh, H., \& Jeong, Y. C. (2007). Inside the iron cage: Organizational political dynamics and institutional changes in presidential selection systems in Korean universities, 1985-2002. Administrative Science Quarterly, 52(2), 286-323. doi:10.2189/asqu.52.2.286

Kodeih, F., \& Greenwood, R. (2014). Responding to institutional complexity: The role of identity. Organization Studies, 35(1), 7-39. doi:10.1177/0170840613495333 
Kostova, T., Roth, K., \& Dacin, M. T. (2008). Institutional theory in the study of multinational corporations: A critique and new directions. Academy of Management Review, 33(4), 994-1006. doi:10.5465/ AMR.2008.34422026

Kraatz, M. S., \& Block, E. S. (2008). Organizational implications of institutional pluralism. In: W. Powell, J. A. Colyvas, R. Greenwood, C. Oliver, K. Sahlin \& R. Suddaby, (Orgs.), The Sage handbook of organizational institutionalism (pp. 243-275). London: Sage.

Krein, J. D. (2007). Tendências recentes nas relações de emprego no Brasil: 1990-2005. (Tese de Doutorado). Instituto de Economia, Universidade Estadual de Campinas. Disponível em: http://repositorio. unicamp.br/jspui/handle/REPOSIP/285517

Langley, A. (1999). Strategies for theorizing from process data. Academy of Management Review, 24(4), 691-710. doi:10.5465/AMR.1999.2553248

Lavelle, J., Turner, T., Gunnigle, P., \& McDonnell, A. (2012). The determinants of financial participation schemes within multinational companies in Ireland. International Journal of Human Resource Management, 23(8), 1590-1610. doi:10.1080/09585192.2012.661991

Lawrence, T. B., Winn, M. I., \& Jennings, P. D. (2001). The temporal dynamics of institutionalization. Academy of Management Review, 26(4), 624-644. doi:10.5465/AMR.2001.5393901

Lawrence, T. B., Mauws, M. K., Dyck, B., \& Kleysen, R. F. (2005). The politics of organizational learning: Integrating power into the 4 I framework. Academy of Management Review, 30(1), 180-191. doi:10.5465/ AMR.2005.15281451

Locke, E. A., \& Latham, G. P. (2002). Building a practically useful theory of goal setting and task motivation: A 35-year odyssey. American Psychologist, 57(9), 705-717. doi:10.1037/0003-066X.57.9.705

Locke, E. A., Latham, G. P., \& Erez, M. (1988). The Determinants of Goal Commitment. Academy of Management Journal, 13(1), 23-39. doi: 10.5465/amr.1988.4306771

Lounsbury, M. (2002). Institutional transformation and status mobility: The professionalization of the field of finance. Academy of Management Journal, 45(1), 255-266. doi:10.2307/3069295

Lounsbury, M. (2007). A tale of two cities: Competing logics and practice variation in the professionalizing of mutual funds. Academy of Management Journal, 50(2), 289-307. doi:10.5465/AMJ.2007.24634436

Maguire, S., Hardy, C., \& Lawrence, T. B. (2004). Institutional entrepreneurship in emerging fields: HIV/AIDS treatment advocacy in Canada. Academy of Management Journal, 47(5), 657-679. doi:10.2307/20159610

Maguire, S., \& Hardy, C. (2009). Discourse and deinstitutionalization: The decline of DDT. Academy of Management Journal, 52(1), 148-178. doi:10.5465/AMJ.2009.36461993

Marquis, C., \& Lounsbury, M. (2007). Vive la résistance: Competing logics and the consolidation of U.S. community banking. Academy of Management Journal, 50(4), 799-820. doi:10.5465/AMJ.2007.26279172

McPherson, C. M., \& Sauder, M. (2013). Logics in action: Managing institutional complexity in a drug court. Administrative Science Quarterly, 58(2), 165-196. doi:10.1177/0001839213486447

Meyer, J., \& Rowan, B. (1977). Institutionalized organizations: Formal structure as myth and ceremony. American Journal of Sociology, 83(2), 340-363.

Motta, F. C. P., Alcadipani, R., \& Bresler, R. B. (2001). A valorização do estrangeiro como segregação nas organizações. Revista de Administração Contemporânea, 5(SPE), 59-79.

Observatório Social. (2004). Comportamento social e trabalhista da empresa Roberto Bosch Ltda. Relatório Geral de Observação. Disponível em: http://www.observatoriosocial.org.br/sites/default/files/01-03-2004_ 06-bosh-comportamento_social_trabalhista.pdf 
Ocasio, W., Loewenstein, J., \& Nigam, A. (2015). How streams of communication reproduce and change institutional logics: The role of categories. Academy of Management Review, 40(1), 28-48. doi:10.5465/ amr.2013.0274

Oliver, C. (1992). The antecedents of deinstitutionalization. Organization Studies, 13(4), 563-588. doi:10.1177/017084069201300403

Oliver, C. (1991). Strategic responses to institutional processes. Academy of Management Review, 16(1), 145-179.

Oliveira, L. M. B. D. (2001). Estratégias e práticas de remuneração utilizadas pelas empresas brasileiras. Organizações \& Sociedade, 8(21), 97-108.

O'Mahony, S., \& Bechky, B. A. (2008). Boundary organizations: Enabling collaboration among unexpected allies. Administrative Science Quarterly, 53(3 SPEC. ISS.), 422-459. doi:10.2189/asqu.53.3.422

Oyadomari, J. C. T., Lima, R. D., Aguiar, A. D., \& Baldussi, C. A. (2012). Modelo de remuneração variável atrelada ao balanced scorecard. Tecnologias de Administração e Contabilidade, 2(1), 33-49.

Pache, A., \& Santos, F. (2010). When worlds collide: The internal dynamics of organizational responses to conflicting institutional demands. Academy of Management Review, 35(3), 455-476. doi:10.5465/ AMR.2010.51142368

Patton, M. (2002). Qualitative research and evaluation methods. London: Sage Publications.

Pina, J. A., \& Stotz, E. N. (2011). Participação nos lucros ou resultados e banco de horas: Intensidade do trabalho e desgaste operário. Revista Brasileira de Saúde Ocupacional, 36(123), 162-176.

Poutsma, E., Ligthart, P., \& Schouteten, R. (2005). Employee Share Schemes in Europe. The Influence of US Multinationals. Management Revue, 16(1), 99-122.

Powell, W. W., \& Colyvas, J. A. (2008). Microfoundations of institutional theory. In: R. Greenwood, C. Oliver, K. Sahlin, \& R. Suddaby. (Eds.). The SAGE Handbook of Organizational Institutionalism (pp. 276-298). London: Sage.

Raaijmakers, A. G. M., Vermeulen, P. A. M., Meeus, M. T. H., \& Zietsma, C. (2015). I need time! Exploring pathways to compliance under institutional complexity. Academy of Management Journal, 58(1), 85-110. doi:10.5465/amj.2011.0276

Reay, T., \& Hinings, C. R. (2005). The recomposition of an organizational field: Health care in Alberta. Organization Studies, 26(3), 351-384. doi:10.1177/0170840605050872

Reay, T., \& Hinings, C. R. (2009). Managing the rivalry of competing institutional logics. Organization Studies, 30(6), 629-652. doi:10.1177/0170840609104803

Reis, M. T. Neto, \& Marques, A. L. (2004). A remuneração variável e sua contribuição para a melhoria da gestão. Revista de negócios, Blumenau, 9(1), 05-18.

Sandeep, M. S., \& Ravishankar, M. N. (2014). The continuity of underperforming ICT projects in the public sector. Information and Management, 51(6), 700-711. doi:10.1016/j.im.2014.06.002

Santos, W. E. F. (2011). Os programas de "Participação nos Lucros ou Resultados" (PLR) no setor bancário brasileiro de 1994 a 2010: da implantação ao modelo atual. Trabalho apresentado no Primeiro Circuito de Debates Acadêmicos, CODE/Instituto de Pesquisas Avançadas. Disponível em: http://www.ipea.gov.br/ code2011/chamada2011/pdf/area11/area11-artigo10.pdf

Santos, W. E. F. (2012). Entre a hegemonia e o despotismo: Os programas de participação nos Iucros ou resultados (PLR) no setor bancário (Dissertação de Mestrado). Faculdade de Filosofia, Letras e Ciências Humanas, Universidade de São Paulo. 
Seo, M., \& Creed, W. E. D. (2002). Institutional contradictions, praxis, and institutional change: A dialectical perspective. Academy of Management Review, 27(2), 222-247. doi:10.5465/AMR.2002.6588004

Martins, S. S. (2000). Participação nos lucros ou resultados: Oportunidade ou desafio para o movimento sindical? Revista de Administração Contemporânea, 4(3), 47-65.

Smets, M., Morris, T., \& Greenwood, R. (2012). From practice to field: A multilevel model of practice-driven institutional change. Academy of Management Journal, 55(4), 877-904. doi:10.5465/amj.2010.0013

Smets, M., Jarzabkowski, P., Burke, G. T., \& Spee, P. (2015). Reinsurance trading in Lloyd's of London: Balancing conflicting-yet-complementary logics in practice. Academy of Management Journal, 58(3), 932-970. doi:10.5465/amj.2012.0638

Suddaby, R., \& Greenwood, R. (2005). Rhetorical strategies of legitimacy. Administrative Science Quarterly, 50(1), 35-67. doi:10.2189/asqu.2005.50.1.35

Tadeucci, M. S. R. (2006). Programas de participação nos resultados: Um estudo em empresas médias. Revista Brasileira de Gestão e Desenvolvimento Regional, 1(1), 71-83.

Tilcsik, A. (2010). From ritual to reality: Demography, ideology, and decoupling in a post-communist government agency. Academy of Management Journal, 53(6), 1474-1498. doi:10.5465/amj.2010.57318905

Thornton, P. H. (2002). The rise of the corporation in a craft industry: Conflict and conformity in institutional logics. Academy of Management Journal, 45(1), 81-101. doi:10.2307/3069286

Thornton, P. H. (2004). Markets from culture: Institutional logics and organizational decisions in higher education publishing. Redwood City: Stanford University Press.

Thornton, P. H., \& Ocasio, W. (2008). Institutional logics. In: R. Greenwood, C. Oliver, K. Sahlin, \& R. Suddaby. (Eds.). The SAGE Handbook of Organizational Institutionalism (pp. 99-128). London: Sage.

Thornton, P. H., Ocasio, W., \& Lounsbury, M. (2015). The institutional logics perspective. In: R.A. Scott, \& S.M. Kosslyn. (Eds.). Emerging trends in the social and behavioral sciences: An interdisciplinary, searchable, and linkable resource (pp. 1-22). doi:10.1002/9781118900772.etrds0187

Westphal, J. D., \& Zajac, E. J. (1993). Substance and symbolism in CEOs' long-term incentive plans. Academy of Management Proceedings, 1993(1), 232-236.

Westphal, J. D., \& Zajac, E. J. (2001). Decoupling policy from practice: The case of stock repurchase programs. Administrative Science Quarterly, 46(2), 202-228. doi:10.2307/2667086

Wood, T., Jr., \& Caldas, M. P. (2002). Adopting imported managerial expertise in developing countries: The brazilian experience. Academy of Management Executive, 16(2), 18-32. doi:10.5465/AME.2002.7173487

Wood, T., Jr., \& Picarelli, V., Filho. (1996). Remuneração e estratégica: A nova vantagem competitiva. São Paulo: Atlas.

Yu, K. (2013). Institutionalization in the context of institutional pluralism: Politics as a generative process. Organization Studies, 34(1), 105-131. doi:10.1177/0170840612464755

Zilber, T. B. (2017). How institutional logics matter: a bottom-up exploration. In: J. Gehman, M. Lounsbury, \& R. Greenwood (Org.). How Institutions Matter! (pp. 137-156, Research in the Sociology of Organizations, v. 48). Bingley: Emerald Group.

Zylberstajn, H. (2002). The brazilian case: Performance pay as worker's right. In: M. Brown, \& J. S. Heywood. (Orgs.). Paying for performance: An international comparison (pp. 52-89). New York: M. E. Sharp.

Zylberstajn, H. (2003). PLR e o mercado de capitais: Desenhando a poupança participativa. In: J.P.Z. Chahad, \& P. Pichetti. (Orgs.) Mercado de trabalho no Brasil: Padrões de comportamento e transformações institucionais (pp. 236-260). São Paulo: FIPE, LTR. 


\section{Sobre as Autoras}

\section{Rosana Carmen de Meiroz Grillo Gonçalves}

Professora do Departamento de Contabilidade da Faculdade de Economia, Administração e Contabilidade de Ribeirão Preto, Universidade de São Paulo. Livre Docente em Controladoria e Sistemas de Informação pela Faculdade de Economia, Administração e Contabilidade de Ribeirão Preto da Universidade de São Paulo. Email: rosanagg@usp.br. ORCID: 0000-0001-5992-1048

\section{Mariana Simões Ferraz do Amaral Fregonesi}

Professora do Programa de Mestrado Profissional de Gestão em Organizações de Saúde da Faculdade de Medicina de Ribeirão Preto, e do Departamento de Contabilidade da Faculdade de Economia, Administração e Contabilidade de Ribeirão Preto, ambas da Universidade de São Paulo. Doutora em Contabilidade e Controladoria pela Faculdade de Economia, Administração, Contabilidade e Atuária da Universidade de São Paulo. Email: mafregonesi@usp.br. ORCID: 0000-0001-6704-4196

\section{Vanessa Berlato Moreira}

Professora da Faculdade Anhanguera de Jundiaí. Mestre em Ciências Contábeis pela Faculdade de Economia, Administração e Contabilidade de Ribeirão Preto da Universidade de São Paulo. Email: vanberlato@gmail.com. ORCID: 0000-0002-4785-9272 